\title{
PROVA TESTEMUNHAL - PROSTITUTA OU PRINCESA?
}

Brenda Tahis Osorio Lima de Oliveira, Daniela Rosa de Carvalho Marinho, Diego Dutra Silva Pappotti, Érica da Silva Poisler, Gerson Gomes da Silva Junior, Naiara Oliveira Shigueura, Marcelo Farina de Medeiros

Universidade do Oeste Paulista - UNOESTE. Curso de Direito, Presidente Prudente - SP.

\section{RESUMO}

Este artigo visa apresentar a evolução histórica da prova testemunhal, componente de suma importância para a busca da verdade e a efetivação da justiça. Desde sua origem, o ser humano pratica um dos seus piores defeitos: a mentira. Se o ser humano se conscientizasse e deixasse de mentir ao menos em juízo, como ocorre em alguns países, indubitavelmente, os magistrados brasileiros não seriam induzidos a erro, aplicando a lei com mais eficácia, e tal prova seria considerada a princesa. Mas pior do que simplesmente ocultar a verdade com informação inverídica, é mentir em juízo, o que certamente acarreta em graves danos à relação jurídica entre autor, réu e Estado, prejudicando o andamento do processo e, principalmente, a busca pela verdade e pela justiça, dando à prova testemunhal a alcunha de prostituta das provas.

Palavras-chave: partes, prova, testemunhal, processo, civil, oitiva, depoimento.

\section{TESTIMONIAL EVIDENCE - PRINCESS OR PROSTITUTE?}

\begin{abstract}
This article presents the historical evolution of testimonial evidence, paramount importance component for search for truth and the realization of justice. Since the origin, the human practices one of his worst faults: lying. If the human would be aware and stop lying at least to the Court, as in some countries, undoubtedly, Brazilian judges would not be misled by applying the law more effectively, and such evidence would be considered a princess. But worse than simply hide the truth with untrue information, is lying in Court, which certainly leads to serious damage to the legal relationship between author, defendant and State, harming the progress of the process and, especially, the search for truth and justice, giving the testimonial proof nicknamed prostitute of evidence.
\end{abstract}

Keywords: parties, testimonial, process, civil, hearsay testimony. 


\section{INTRODUÇÃO}

Com a evolução da sociedade, as lides passaram a ocupar espaço nas relações humanas pelo vínculo jurídico. Para resolver uma lide, pretensão a um direito resistida, mister se faz a apresentação das provas, para garantir a legitimidade daquele direito, entre elas, a prova testemunhal, tão importante para o descobrimento da verdade e a busca por justiça.

A problematização surge, no entanto, quando se indaga o que seria a verdade? A que ponto a prova testemunhal pode ser considerada uma grande aliada? A testemunha não pode induzir um magistrado ao erro? E se a testemunha também estiver em estado de erro? $\mathrm{E}$ a verdade? Como é feita, então, a busca por justiça?

Sem discutirmos religião, importante se faz lembrar o drama vivido por Jesus em seu julgamento. O povo, enfurecido, pedia sua condenação mesmo estando em estado de erro. Pilatos, o julgador, simplesmente lavou suas mãos, dizendo: "Vox populi, vox Dei”, ou seja, "A voz do povo é a voz de Deus". Marabá, considerado um bandido, foi absolvido e Jesus foi condenado.

A prova testemunhal continuou levantando suas controvérsias quanto ao seu valor. No Direito Canônico, por exemplo, a verdade estava do lado de quem tinha o maior número de testemunhas. A parte que se enquadrasse nessa situação já estava em uma posição favorecida. Considerava-se também o sexo da testemunha. O testemunho do homem tinha um valor muito acima do testemunho da mulher, que era quase desconsiderado, mas acima do testemunho da criança, como também lembra Humberto Theodoro Junior ${ }^{1}$. O testemunho do nobre tinha um valor maior do que o testemunho de uma pessoa comum. Portanto, era pelo número e importância de testemunhas que tornava a parte em posição mais vantajosa. Infelizmente, o que contava era o sexo, a fama, a posição social das testemunhas, entre outras características. Quanto à apreciação da prova pelo julgador, essa era livre, mas com crítica lógica e racional.

Com o passar do tempo e com a evolução do Direito, a prova testemunhal passou a ter igual valor entre as testemunhas. Porém, a prova testemunhal mais valiosa é aquela que mais contribuir para o descobrimento ou a evidência da verdade, ou ainda, efetivar a segurança jurídica. O procedimento para a busca pela justiça é disciplinado por lei. Assim, o presente trabalho, por meio do método dedutivo, histórico e empírico revela a importância da prova testemunhal, não obstante a diversidade de percepção e possibilidade de comprometimento das pessoas que dão testemunho".

\footnotetext{
${ }^{1}$ Theodoro Junior, Humberto. Curso de Direito Processual Civil: Teoria Geral do Direito Processual Civil, Processo de Conhecimento, 2ª ed. eletrônica - Vol. 1, Rio de Janeiro: Editora Forense, 2003, p. 425 a 434, e 448 a 449. 
A PROVA TESTEMUNHAL NO BRASIL

\section{Conceito de Testemunha}

O doutrinador Fábio Vasconcelos Menna ${ }^{2}$ define de forma precisa o conceito de testemunha: É a pessoa física capaz, independente de condição econômica, raça, religião ou sexo, que pode depor, desde que não esteja no rol das pessoas suspeitas ou impedidas. Não se confunde com uma das partes do processo, pois não pode ter qualquer interesse na demanda. Sendo devidamente intimada, não prestar seu depoimento, poderá, dependendo do caso, ser coercitivamente conduzida a juízo para as declarações necessárias, para a comprovação da verdade dos fatos alegados.

\section{Requisitos}

Pessoa Física - a pessoa deve ser pessoa física. Se for jurídica, não serve como testemunha. No máximo que a pessoa jurídica faz, é prestar informação.

Capacidade - a pessoa além de física, deve ser capaz. Sendo incapaz, não pode ser testemunha, sendo apenas um mero informante.

Desinteresse - a testemunha não pode ter interesse algum na controvérsia. Deve ser desinteressada.

Esclarecimentos sobre os fatos - a pessoa deve apenas falar os fatos, não podendo ela falar sobre direitos.

Chamamento - alguns autores apresentam como requisito da testemunha que a pessoa deve ser chamada a depor.

Conhecimento do fato ${ }^{3}$ - esse requisito diz respeito que a pessoa deve ter conhecimento do fato direto ou indiretamente. A testemunha deve ter consciência em dizer a verdade e versar sobre os fatos que adquiriu com seus próprios sentidos. No caso a pessoa que viu, pelo sentido visual, pelo que ouviu, usando sentido auditivo, e pelo que sentiu, usando sentido gustativo, olfativo ou sensitivo. Basta-se que a pessoa tenha conhecimento do fato, não importando muitos os sentidos pelo qual ela obteve esses conhecimentos.

Sem esses requisitos não haverá testemunha e, por consequência, não haverá prova testemunhal.

\footnotetext{
${ }^{2}$ Menna, Fábio de Vasconcelos. Elementos do Direito: 6ạ Edição, Editora Arx Siciliano, 2007, p. 90 a 92.

3 Junior, Sidnei Amendoreira, Manual de Direito Processual Civil, Vol. 2, Edição Eletrônica formato Epub, São Paulo: Editora Saraiva, 2012, Capítulo 37. 


\section{Conceito de Prova Testemunhal}

A prova testemunhal é feita por oralidade e pessoalidade, só se considerando verdadeira sua prova testemunhal sendo realizada em juízo. Se não houver um juiz presenciando essa oralidade, não há do que se falar em prova testemunhal, como defende Gelson Amaro de Souza ${ }^{4}$.

A testemunha tem valor considerável no processo brasileiro. Seu valor é definido de acordo com a relevância de sua participação ou conhecimento dos fatos. Mas há restrições e todo o procedimento para obter tal prova. Em outras palavras, a prova testemunhal continua sendo fundamental, o juiz dará o valor que merecer, em comparação com os demais elementos de afirmação, observando o livre convencimento motivado, como lembra Marcus Vinícius Gonçalves 5 .

A testemunha tem o dever de dizer a verdade. O seu depoimento não tem como escopo favorecer a parte que a arrolou, devendo vir a juízo apenas para narrar a verdade sobre aquilo que sabe, sendo imparcial, sob pena de responder pelo crime de falso testemunho (Art. 342 do Código Penal). O maior de 16 (dezesseis) e menor de 18 (dezoito) pode também ser testemunha no processo, porém fica afastada a ocorrência do referido delito, dada a inimputabilidade do mesmo. Na realidade, para cumprir a função jurisdicional, o magistrado necessitará verificar a procedência do pedido, ou seja, a demonstração das alegações fáticas.

\section{PRODUÇÃO DE PROVA TESTEMUNHAL}

\section{Requerimento da Prova}

O autor deve requerer a prova testemunhal na inicial, e o réu, na contestação. Porém, eventual omissão não gera a perda de requerê-la oportunamente, porque o autor conhecerá os fatos contravertidos depois da resposta do réu, e se a prova testemunhal será necessária. As partes poderão arrolar no máximo 10 (dez) testemunhas, e o juiz poderá limitar a oitiva de apenas 3 (três) testemunhas para a comprovação de cada fato alegado.

Todas as perguntas direcionadas as testemunhas deverão ser feitas pelo juiz, este podendo indeferir quando achar que a pergunta feito pelo advogado da parte for impertinente, mas a pergunta mesmo que indeferida deverá ser registrada. Se, contudo, na sentença o juiz considerar que não foi demonstrado tal determinado fato que seria tido através daquela pergunta que foi indeferida, sendo assim estará caracterizado o cerceamento do direito de defesa da parte, ou seja, estará diminuído o direito de defesa da parte.

\footnotetext{
${ }^{4}$ Souza, Gelson Amaro de, Curso de Direito Processual Civil, Editora Data Juris, 2a edição, São Paulo, 1.998 , p. 710 a 721.

${ }^{5}$ Gonçalves, Marcus Vinicius Rios. Direito Processual Civil Esquematizado. São Paulo: Saraiva, 2013, p. 361 a 376. 
Antes de iniciar a colheita de depoimentos das testemunhas, as mesmas passam por uma fase de qualificação, que é onde o juiz vai analisar se há algum impedimento ou suspeição da testemunha. Logo após a qualificação a parte contraria daquela que a arrolou poderá contraditala, arguindo o motivo que a impede a sua oitiva. Posteriormente o juiz decidirá determinando a colheita do depoimento, ou dispensando-o. Uma vez deferida a colheita da prova, antes do depoimento a testemunha deve prestar compromisso de dizer somente a verdade, dizer tudo aquilo que sabe, devendo ser advertida sobre as penas do falso testemunho.

\section{RESTRIÇÕES À OUVIDA DE TESTEMUNHAS}

Qualquer pessoa pode ser ouvida como testemunha, porém, há três circunstâncias que impedem a sua ouvida: disposto no art.405 e parágrafos, CPC (Incapacidade - § 1ㅇ, Impedimento § 2ㅇe e Suspeição - § 3ํ).

São suspeitos, segundo o CPC: aquele que já fora condenada pelo crime de falso testemunho; aquele que não for digno de boa fé; aquele que for amigo íntimo ou inimigo capital; e aquele que tiver certo interesse no litígio. E no rol das testemunhas impedidas estão: o cônjuge e os parentes, até terceiro grau; quem for parte, no caso de litisconsórcio uma parte testemunhar para comprovar fatos alegados; aquele que intervém em nome da parte (curador, tutor e/ou mandatário).

\section{Direitos e Deveres da Testemunha}

A lei reputa o depoimento prestado pela testemunha como serviço público (art.419, parágrafo único). Por isso, não poderá sofrer perda de salário e nem desconto no tempo de serviço. Ser-lhe-á dado um atestado, quando necessário, e a parte que a arrolou poderá ressarci-la das despesas que teve para o comparecimento, pagá-las logo que arbitradas, ou depositar o valor em cartório, no prazo de três dias, na forma do art. 419, do CPC, por comparecer em audiência, isto é, quando sujeita ao regime trabalhista.

O seu mais importante dever: dizer a verdade. A testemunha tem a obrigação de dizer somente a verdade, sob pena de falso testemunho (art. 415 , do CPC) se contrário ocorrer. Se a testemunha for menor de dezoito anos, o juiz poderá sujeita-la às medidas do estatuto da criança e do adolescente. 
Acareação

Quando se tratar de fatos relevantes para o processo e verificar-se divergência entre duas ou mais testemunhas, ou entre as testemunhas e a parte, o juiz de ofício ou a requerimento da parte poderá determinar a acareação, que consiste no confronto entre as pessoas que prestaram depoimentos divergentes. Assim, será esclarecida qual a versão sobre a verdade dos fatos. A acareação deve ser feita na própria audiência, e as testemunhas que já haviam prestado seus depoimentos só serão liberadas após o encerramento da mesma (art. 418, parágrafo único, do CPC).

\section{DIFERENÇAS ENTRE DEPOIMENTO PESSOAL E PROVA TESTEMUNHAL}

As características entre os dois meios de prova são muito parecidos e há quem se confunda em seus estudos. Luiz Rodrigues Wambier ${ }^{6}$ esclarece qualquer dúvida a respeito: apesar da produção ser efetuada do mesmo modo, a testemunha não deve proferir opiniões ou juízos de valor, limitando-se apenas a relatar os fatos que sabe. Já no depoimento pessoal, o juiz pode indagar se a parte tomou das devidas precauções de realizar um negócio jurídico, por exemplo, ou se tinha ciência do risco que correria por algum ato jurídico realizado por erro, em lides que discutam sua anulação. O que ambos os meios de prova têm em comum é a possibilidade de avaliar a boa-fé de quem fornece tais informações ou compreender as razões que levam a parte a se comportar de tal maneira.

\section{CONCLUSÃO}

É notório e indiscutível que a prova testemunhal é um dos meios mais antigos e utilizados. Seu valor tem se aprimorado com o passar do tempo, de acordo com a evolução da sociedade que modela o Direito, e este, por sua, vez, modela e educa a sociedade. Mas por que ela ainda é considerada a "prostituta das provas"? Por que não considerá-la como "princesa" com a recepção do Novo Código de Processo Civil?

A raiz da justiça está na própria sociedade. Porém, enquanto esta não por em prática a ética e o respeito, a prova testemunhal continuará tendo sua fama manchada juridicamente em obras doutrinárias. Quiçá um dia, a sociedade evolua mais uma vez, e de forma positiva, dando o devido valor a esse meio de prova tão discutido, e auxiliando, principalmente, na decisão dos

\footnotetext{
${ }^{6}$ Wambier, Luiz Rodrigues. Curso Avançado de Processo Civil: Teoria Geral do Processo e Processo de Conhecimento, v.1 / Luiz Rodrigues Wambier, Eduardo Talamini, Flávio Renato Correia de Almeida; coordenação Luiz Rodrigues Wambier - 10. Ed., ver., atual e ampl. - São Paulo: Editora Revista dos Tribunais, 2008 - pág. 475. 
magistrados brasileiros, os maiores garantidores da justiça desta tão amada República Federativa do Brasil.

\section{REFERÊNCIAS}

Código Brasileiro de Processo Civil, Lei no 5.869, de 11 de janeiro de 1.973.

GONÇALVEs, Marcus Vinicius Rios. Direito Processual Civil Esquematizado. São Paulo: Saraiva, 2013, p. 361 a 376.

JUNIOR, Sidnei Amendoreira, Manual de Direito Processual Civil, Vol. 2, Edição Eletrônica formato Epub, São Paulo: Editora Saraiva, 2012, Capítulo 37.

MENNA, Fábio de Vasconcelos. Elementos do Direito: 6a Edição, Editora Arx Siciliano, 2007, p. 90 a 92.

SOUZA, Gelson Amaro de, Curso de Direito Processual Civil, Editora Data Juris, 2a edição, São Paulo, 1.998, p. 710 a 721.

THEODORO JUNIOR, Humberto. Curso de Direito Processual Civil: Teoria Geral do Direito Processual Civil, Processo de Conhecimento, 2a ed. eletrônica - Vol. 1, Rio de Janeiro: Editora Forense, 2003, p. 425 a 434, e 448 a 449.

WAMBIER, Luiz Rodrigues. Curso Avançado de Processo Civil: Teoria Geral do Processo e Processo de Conhecimento, v.1 / Luiz Rodrigues Wambier, Eduardo Talamini, Flávio Renato Correia de Almeida; coordenação Luiz Rodrigues Wambier - 10. Ed., ver., atual e ampl. - São Paulo: Editora Revista dos Tribunais, 2008 - pág. 475. 